\title{
Numerical Analysis of Welding Residual Stress and Distortion in Laser+GMAW Hybrid Welding of Aluminum Alloy T-Joint
}

\author{
Guoxiang $X U^{1 \dagger \dagger}$, Chuansong $W U^{2)}$, Xuezhou $M A^{1)}$ and Xuyou $W A N G^{3)}$
}

1) Key Laboratory of Advanced Welding Technology of Jiangsu Province, Jiangsu Univeristy of Science and Technology, Zhenjiang 212003, China

2) Institute of Advanced Welding Technology, Shandong University, Jinan 250061, China

3) Harbin Welding Institute, China Academy of Machinery Science \& Technology, Harbin 150080, China

[Manuscript received 19 September 2012, in revised form 23 January 2013]

(c) The Chinese Society for Metals and Springer-Verlag Berlin Heidelberg

\begin{abstract}
A 3-D finite element model is developed to predict the temperature field and thermally induced residual stress and distortion in laser+GMAW hybrid welding of 6061-T6 aluminum alloy T-joint. And the characteristics of residual stress distribution and deformation are numerically investigated. In the simulation, the heat source model takes into account the effect of joint geometric shape and welding torch slant on the heat flux distribution and a sequentially coupled thermo-mechanical method is used. The calculated results show that higher residual stress is distributed in and surround the weld zone. Its peak value is very close to the yield strength of base metal. Besides, a large deformation appears in the middle and rear part of the weldment.
\end{abstract}

KEY WORDS: Hybrid welding; Residual stress; Welding distortion; Aluminum alloy T-joint; Numerical simulation

\section{Introduction}

Aluminum alloy T-welded structure is increasingly used in automotive, petroleum storage, railway vehicles, bridges and other fields ${ }^{[1]}$. Thus, it is of great significance to achieve the high quality and high efficiency welding of aluminum alloy T-joint. However, compared to the simple joint, the welding defects are generated easily in the $\mathrm{T}$-joint welding of aluminum alloy due to the complexity of its physical process $^{[2,3]}$. As a new joining technology, laser+gas metal arc welding (GMAW) hybrid welding can prevent the formation of the welding defect in the case of high welding speed ${ }^{[4]}$, therefore being a promising approach to fabricate the T-joint of aluminum alloy ${ }^{[5]}$.

Integrating laser welding and GMAW into one system, laser+GMAW hybrid welding combines the merits of two welding processes and compensates deficiencies of each individual. Reported advantages of this new process are an increase in the welding speed,

\footnotetext{
† Corresponding author. Assistant Prof., Ph.D.; Tel: +86 511 84491208, Fax: +86 511 84407381; E-mail address: xugxiang@163.com (Guoxiang XU)
}

DOI: $10.1007 / \mathrm{s} 40195-012-0166-5$ the weldable thickness, the gap bridging ability, the weld quality with reduced susceptibility to pores and cracks, as well as the process stability and efficiency ${ }^{[4,6,7]}$. Extensive experimental and calculated studies have been conducted on laser+GMAW hybrid welding, including the influence of process parameters on weld formation ${ }^{[8-10]}$, thermal field ${ }^{[11,12]}$, fluid flow in the weld pool ${ }^{[13,14]}$, residual stress ${ }^{[15,16]}$, distortion $^{[15]}$ and so on ${ }^{[17]}$. However, most of the previous studies are mainly based on the bead-onplate welding or simple joint welding, and there is little study involving the laser+GMAW hybrid welding of aluminum alloy T-joint, except for its numerical simulation $^{[18]}$. Welding induced residual stress and distortion can greatly affect the final welding quality and service behavior of the welded structure ${ }^{[16,18]}$. Therefore, it has important theoretical and practical value to study the welding residual stress and deformation for deep understanding of hybrid welding process of complex joint.

In this study, a thermo-mechanical finite element model is developed to predict the temperature field and thermally induced residual stress and distortion in laser+GMAW hybrid welding of aluminum alloy T- 
Table 1 Chemical compositions (wt.\%) of 6061-T6 aluminum alloy and ER5356 wire

\begin{tabular}{ccccccccccc}
\hline Materilas & $\mathrm{Si}$ & $\mathrm{Fe}$ & $\mathrm{Cu}$ & $\mathrm{Mn}$ & $\mathrm{Mg}$ & $\mathrm{Cr}$ & $\mathrm{Zn}$ & $\mathrm{Ti}$ & Others & $\mathrm{Al}$ \\
\hline 6061-T6 & $0.4-0.8$ & 0.7 & $0.15-0.4$ & 0.15 & $0.8-1.2$ & $0.04-0.35$ & 0.25 & 0.15 & 0.15 & Bal. \\
ER5356 & 0.25 & 0.4 & 0.1 & $<0.13$ & 4.9 & 0.065 & 0.1 & 0.11 & 0.15 & Bal. \\
\hline
\end{tabular}

joint, and the characteristics of residual stress distribution and deformation are numerical analyzed, which will lay a foundation for process optimization of hybrid welding of aluminum alloy T-joint.

\section{Experimental}

The base metal and the filler materials used in the present study are 6061-T6 aluminum alloy and ER5356 aluminum alloy welding wire. Their chemical compositions are listed in Table 1. Nd:YAG laser+GMAW hybrid welding was conducted on the aluminum alloy T-specimens, as shown Fig. 1. The flange and web had dimensions of $300 \mathrm{~mm} \times 100 \mathrm{~mm} \times 2 \mathrm{~mm}$ and $300 \mathrm{~mm} \times 50 \mathrm{~mm} \times$ $2 \mathrm{~mm}$, respectively. In the hybrid welding process, laser was in front of arc and hybrid welding torch was titled $30^{\circ}$ with respect to the flange. Metal droplet was transferred in short circuiting mode. Two welding passes were carried out separately with opposite welding direction. The welding parameters were wavelength $1.06 \mu \mathrm{m}$, focus diameter $0.6 \mathrm{~mm}$, focus position- $8 \mathrm{~mm}$, laser-arc distance $1 \mathrm{~mm}$, laser-arc angle $27^{\circ}$, wire diameter $1.2 \mathrm{~mm}$, wire extension $12 \mathrm{~mm}$, peak current $142 \mathrm{~A}$, background current $26 \mathrm{~A}$, average voltage $15 \mathrm{~V}$ and the wire feeding rate $3 \mathrm{~m} / \mathrm{min}$.

\section{Finite Element Modeling}

The residual stresses and distortion in laser+GMAW hybrid T-joint welding of aluminum alloy is investigated by means of thermal elastic plastic finite element method. In order to accurately capture the residual stress and distortion in the T-welded joint, a three-dimensional finite element model is developed. Due to that the dimensional changes during the whole welding process are negligible and mechanical work done is insignificant compared to the thermal energy from the laser and arc, the thermo-mechanical behavior of the weldment during welding is simulated using a sequentially coupled formulation ${ }^{[19]}$. The heat conduction problem is solved independently from the stress problem and phase state to obtain temperature history. But, the formulation takes into account the contributions of the transient temperature field to the stress analysis through thermal expansion, as well as temperature-dependent thermo-physical and mechanical properties. The calculation procedure consists of two steps. First, the temperature field and its history in hybrid welding of aluminum alloy T-joint are computed by the thermal analysis. Then, the calculated temperature history at the first step is taken as a thermal load in the subsequent mechanical elastic-plastic calculation of the residual stress field.

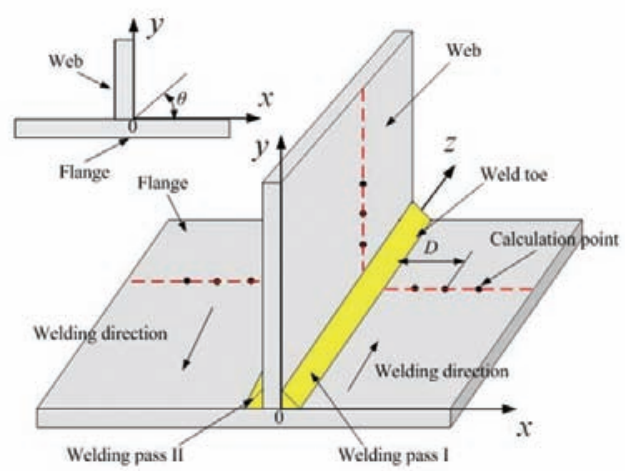

Fig. 1 Schematic diagram of laser+GMAW hybrid welding of aluminum alloy T-joint ( $D$ is the distance of calculation point from weld toe; $\theta$ is the slant angle of hybrid welding gun with respect to the flange)

\subsection{Thermal analysis}

\subsubsection{Heat source model}

As the first step, the temperature field and its history during the hybrid T-joint welding of aluminum alloy is calculated firstly. To assure the accuracy of computed results, it is essential to develop an adaptive heat source model, which needs to describe the heat source for laser welding and GMAW appropriately.

In this study, GMAW heat input is modeled as one transient double-ellipsoid body heat source, which has different distribution parameters for short circuiting peak and background arcs. The heat source rotation is achieved using the coordinate transformation. The equation describing the heat input from GMAW after coordinate rotation is expressed in the following, and its detailed calculation procedure is available in Ref. [18]. In the simulation, the heat source center for GMAW is coincident with the intersection point of welding wire axis and contour line of reforcement (Fig. 2).

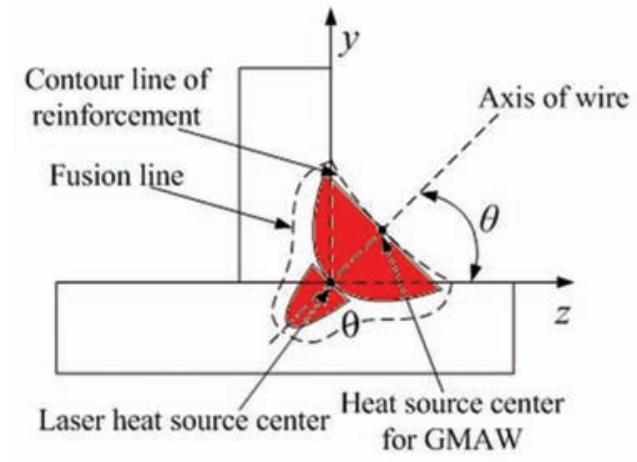

Fig. 2 Sketch map of the heat source action location 


$$
\begin{aligned}
q_{\mathrm{f}}(x, y, z)= & \frac{6 \sqrt{3}\left(f_{\mathrm{f}} Q\right)}{a_{\mathrm{f}} b_{\mathrm{h}} c_{\mathrm{h}} \pi \sqrt{\pi}} \exp \left(-\frac{3(x-v t)^{2}}{a_{\mathrm{f}}^{2}}-\right. \\
& \frac{3\left[\left(y-y_{\mathrm{c}}\right) \cos \theta+\left(z-z_{\mathrm{c}}\right) \sin \theta\right]^{2}}{b_{\mathrm{h}}^{2}}- \\
& \left.\frac{3\left[\left(z-z_{\mathrm{c}}\right) \cos \theta+\left(y-y_{\mathrm{c}}\right) \sin \theta\right]^{2}}{c_{\mathrm{h}}^{2}}\right) x \geq 0
\end{aligned}
$$

$$
\begin{aligned}
& q_{\mathrm{r}}(x, y, z)= \frac{6 \sqrt{3}\left(f_{\mathrm{r}} Q\right)}{a_{\mathrm{r}} b_{\mathrm{h}} c_{\mathrm{h}} \pi \sqrt{\pi}} \exp \left(-\frac{3(x-v t)^{2}}{a_{\mathrm{r}}^{2}}-\right. \\
& \frac{3\left[\left(y-y_{\mathrm{c}}\right) \cos \theta+\left(z-z_{\mathrm{c}}\right) \sin \theta\right]^{2}}{b_{\mathrm{h}}^{2}}- \\
&\left.\frac{3\left[\left(z-z_{\mathrm{c}}\right) \cos \theta+\left(y-y_{\mathrm{c}}\right) \sin \theta\right]^{2}}{c_{\mathrm{h}}^{2}}\right) x \geq 0 \\
& f_{\mathrm{f}}+f_{\mathrm{r}}=2
\end{aligned}
$$

In the peak arc duration,

$$
Q=\eta I_{\mathrm{p}} \bar{U}
$$

In the background arc duration,

$$
Q=\eta I_{\mathrm{b}} \bar{U}
$$

where $q_{\mathrm{f}}$ and $q_{\mathrm{r}}$ are the heat flux distribution functions in the front and rear of the heat source center, respectively; $Q$ is the effective heat input from GMAW, which is different in the peak and background arc durations; $I_{\mathrm{P}}$ is the peak current; $I_{\mathrm{b}}$ is the background current; $\bar{U}$ is the average voltage, $v$ is the welding speed; $a_{\mathrm{f}}, a_{\mathrm{r}}, b_{\mathrm{h}}$ and $c_{\mathrm{h}}$ are the distribution parameters; $t$ is the time, $\left(x_{\mathrm{c}}, y_{\mathrm{c}}, z_{\mathrm{c}}\right)$ is the coordinate of heat source center, $\theta$ is the slanting angle between the hybrid welding gun and the plate of T-joint; $f_{\mathrm{f}}$ and $f_{\mathrm{r}}$ are the heat distribution coefficients.

For laser welding, allowing for the weld beam geometry and macroscopic thermal action, laser heat intensity is assumed as one rotary body heat source based on a certain curve, its peak density value and distribution radius varying along the thickness direction of workpiece. In this study, its thermal action radius is decreased linearly and its peak density is increased in a exponential curve. Similarly, laser heat source model is also rotated to take into account the thermal action characteristic in the case of inclined hybrid gun. The equation for laser heat source model is given in the following and its center is located at the weld root owing to that laser beam can go through to the weld root and then heat the workpiece in the calculation.

$$
\begin{aligned}
& q(x, y, z)=Q_{0} \exp \left(-\frac{\ln (\xi)}{H}\left(\left(y-y_{\mathrm{c}}\right) \cos \theta+\left(z-z_{\mathrm{c}}\right) \sin \theta\right)\right) . \\
& \exp \left(-\frac{3\left((x-v t)^{2}+\left[\left(z-z_{\mathrm{c}}\right) \cos \theta+\left(y-y_{\mathrm{c}}\right) \sin \theta\right]^{2}\right.}{r_{0}^{2}\left[\left(y-y_{\mathrm{c}}\right) \cos \theta+\left(z-z_{\mathrm{c}}\right) \sin \theta\right]}\right)
\end{aligned}
$$

$$
\begin{gathered}
Q_{0}=\frac{3 Q L \ln (\chi)}{\pi\left(1-e^{-3}\right) H\left\{r_{\mathrm{e}}^{2}-r_{i}^{2} \chi-2 \frac{r_{i}-r_{\mathrm{e}}}{\ln (\chi)}\left[r_{\mathrm{e}}-r_{i} \chi-\frac{r_{i}-r_{\mathrm{e}}}{\ln (\chi)}(1-\chi)\right]\right\}} \\
r_{0}(y)=\frac{r_{\mathrm{e}}-r_{i}}{H} y+r_{i}
\end{gathered}
$$

where $q(x, y, z)$ is the heat flux function of laser heat source model, $H$ is the height of heat source, $r_{e}$ and $r_{i}$ are the radii of the heat source top and bottom surfaces, respectively, $\chi$ is the proportional factor between peak power densities at the heat source top and bottom surfaces, $r_{0}(y)$ is the function depicting the change of the heat source radius, $Q_{\mathrm{L}}$ is the effective laser power.

After combining the aforementioned sub-models for GMAW and laser welding respectively, the heat source model for laser+GMAW hybrid welding of aluminum alloy T-joint is built. Fig. 2 shows its action location. And, the interaction between laser beam and arc is indirectly considered by adjusting some distribution parameters appropriately.

\subsubsection{Governing equations and boundary conditions}

To simplify the calculation process and attach importance to the main thermal field feature, only the thermal conduction in transient state is considered, and the fluid flow in the weld pool is ignored. The resulting errors can be controlled in a reasonable limit by developing an appropriate heat source model for hybrid welding of T-joint. The transient thermal conduction equation is given by

$\rho c \frac{\partial T}{\partial t}=\frac{\partial}{\partial x}\left(k \frac{\partial T}{\partial x}\right)+\frac{\partial}{\partial y}\left(k \frac{\partial T}{\partial y}\right)+\frac{\partial}{\partial z}\left(k \frac{\partial T}{\partial z}\right)+S_{\mathrm{H}}$

where $\rho$ is the density, $c$ is the specific heat, $k$ is the thermal conductivity, $T$ is the temperature, $S_{\mathrm{H}}$ is the heat source term, namely the power density of combined volumetric heat source for hybrid welding of T-joint.

The associated boundary condition in this work is expressed as

$$
-k \nabla T \cdot \vec{n}_{\mathrm{t}}=\alpha_{\mathrm{cr}}\left(T-T_{\infty}\right)
$$

where $\nabla$ is the Laplace operator, $\vec{n}_{\mathrm{t}}$ is the normal unit vector to the surfaces, $\alpha_{\mathrm{cr}}$ is the combined heat transfer coefficient by convection and radiation, $T_{\infty}$ is the ambient temperature.

To reduce the computing time in the case of enough numerical precision, an un-uniform mesh is employed in the calculation. A finer mesh is designed at the weld and its vicinity and a coarse mesh is applied at the region far away from the weld bead, shown in Fig. 3. Allowing for the filling of materials by the melted wire, a "death and birth" technique 


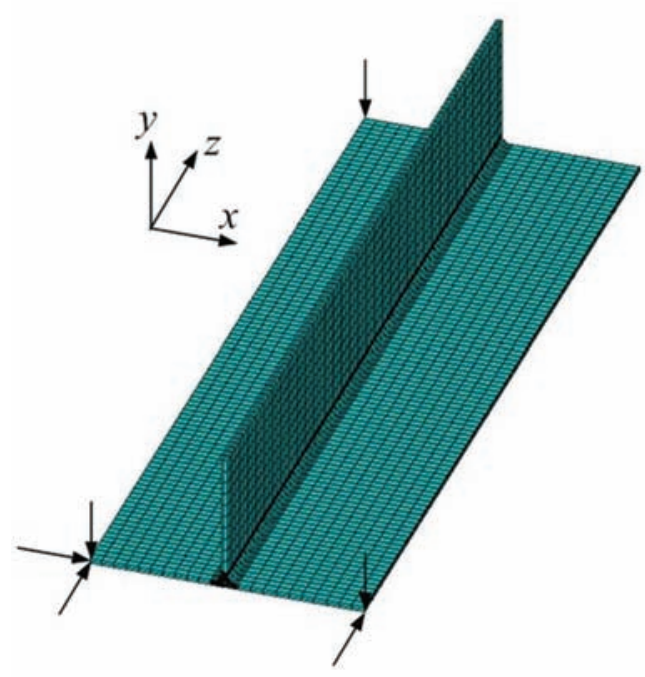

Fig. 3 Finite element mesh of T-welded specimens

is used in the thermal analysis. Initially, all the elements located at the filler material are killed, which almost have no influence on the calculated results. Subsequently, the elements of the filler material are activated segment by segment with the hybrid welding heat source moving to simulate the weld bead formation by the filler material. The temperaturedependent thermal-physical properties of base metal given in Fig. 4 are considered in the model ${ }^{[20]}$.

\subsection{Mechanical analysis}

During the welding process, the total strain increase $\{\mathrm{d} \varepsilon\}$ can be expressed as the sum of the individual components due to elastic, plastic and thermal loadings, respectively, and can be calculated by

$$
\{\mathrm{d} \varepsilon\}=\left\{\mathrm{d} \varepsilon^{\mathrm{e}}\right\}+\left\{\mathrm{d} \varepsilon^{\mathrm{p}}\right\}+\left\{\mathrm{d} \varepsilon^{\mathrm{T}}\right\}
$$

where $\left\{\mathrm{d} \varepsilon^{\mathrm{e}}\right\},\left\{\mathrm{d} \varepsilon^{\mathrm{p}}\right\}$ and $\left\{\mathrm{d} \varepsilon^{\mathrm{T}}\right\}$ are the elastic, plastic and thermal strain increases, respectively.

In the mechanical analysis, the same mesh configuration used in the thermal analysis is employed except for element type. The analysis is performed using the temperature history computed by the thermal analysis as the input information. At the same time, the mechanical constraints are used to prevent rigid body motion, given in Fig. 3. And, in the mechanical simulation, the elastic stress-strain relationship of welded material is assumed to obey the isotropic Hooke's law with temperature-dependent Young's modulus. Thermal strain is taken into account through thermal expansion coefficient. Regarding the plastic behavior, a rate independent plastic model is applied. The yielding behavior of the welded material satisfies the von Mises principle, and a bi-linear hardening law is employed to simulate the strain hardening. Besides, similar to the thermal analysis, the temperature-dependent mechanical properties of materials are used in the mechanical model, as seen in

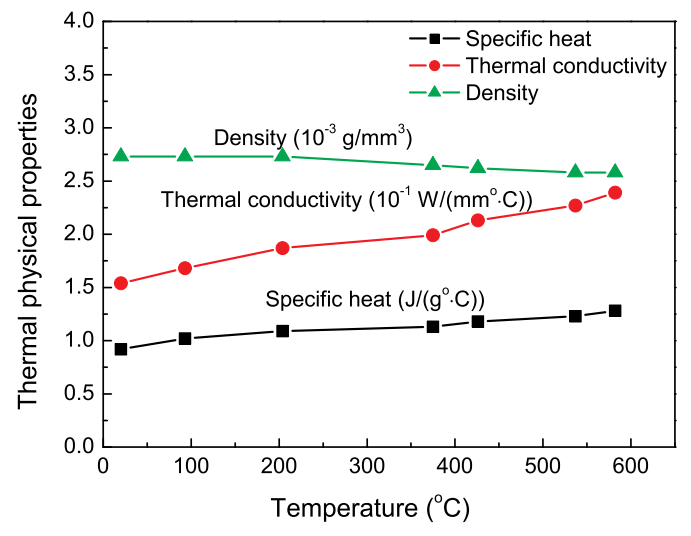

Fig. 4 Temperature-dependent thermal physical properties of 6061-T6 aluminum alloy

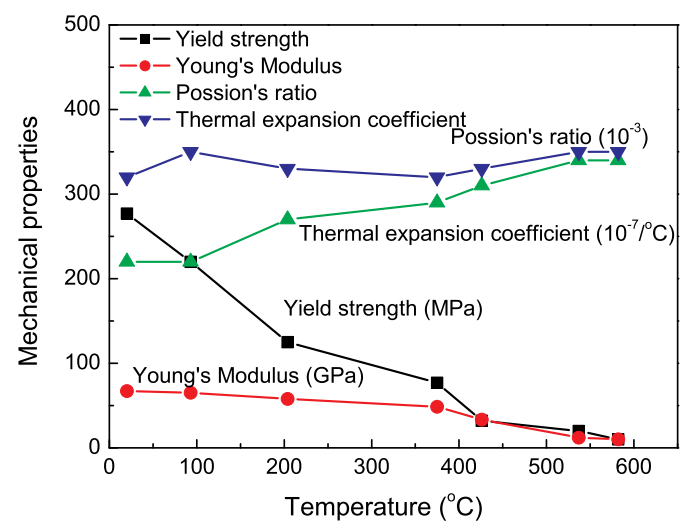

Fig. 5 Temperature-dependent mechanical properties of 6061-T6 aluminum alloy

Fig. 5. The "death and birth" method is also employed to reflect the influence of material filling on the mechanical analysis of hybrid welding of aluminum alloy T-joint.

\section{Results and Discussion}

\subsection{Analysis of hybrid welding residual stress}

The shape and size of weld cross section in laser+GMAW hybrid welding of aluminum alloy Tjoint are calculated using the developed heat source model though ANSYS software, and are compared with the measured data, and both have a good agreement, as shown in Fig. 6, which indicates that, the established heat source model is suitable for calculating the temperature field in hybrid welding of aluminum alloy T-joint, thus ensuring the precision of simulated thermally induced welding residual stress distribution as well as distortion. The computed temperature distribution and thermal cycles for different points on the flange surface at the weld pass I side (seen in Fig. 1) is given in Fig. 7. It is seen that, due to high welding speed, the temperature field during the welding process is narrow. Besides, because the two welding 

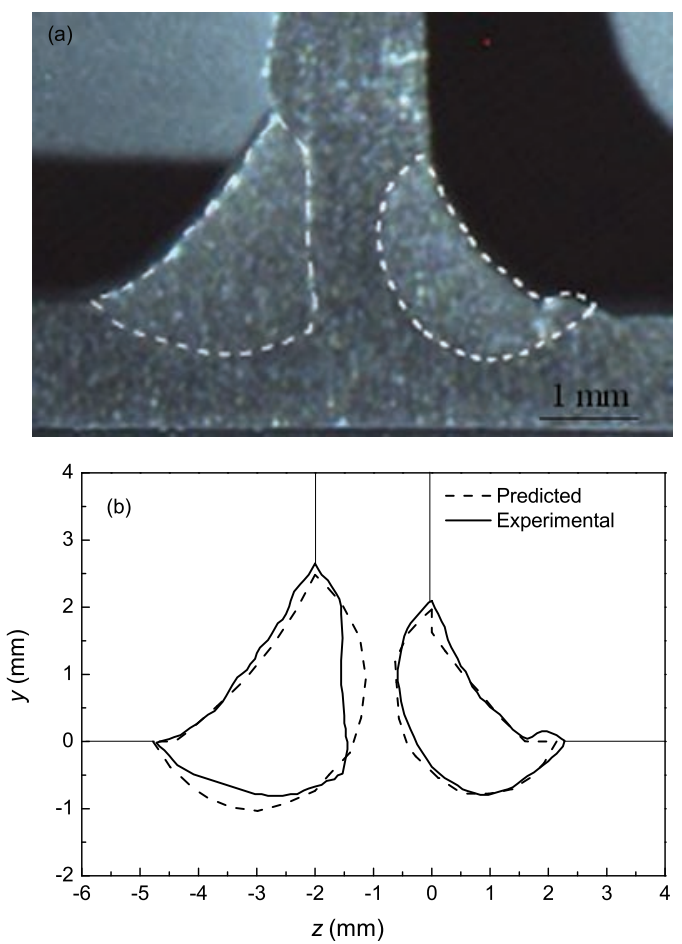

Fig. 6 Macrophotograph of hybrid weld cross section (a) and comparison of the experimental and the calculated data (b)

passes were conducted separately, each point on the workpiece suffers two thermal cycles.

Fig. 8 presents the residual stress component distributions in laser+GMAW hybrid welding of aluminum alloy T-joint. From Fig. 8(a), it is clearly found that, there exits a large tensile residual stress in the welding direction (longitudinal stress) in the weld zone and its vicinity because of the shrinkage of the weld, and its peak values is $274 \mathrm{MPa}$, slightly lower than the yield strength of the base metal. At the region far from weld bead, a compressive stress appears. The distribution of longitudinal residual stress on the flange surface is similar to that on the web surface. Fig. 8(b) and Fig. 8(c) give the contours of stress components in $x$ and $y$ directions, respectively. It is seen that, compared with the stress component in the welding direction, these two stress components are relatively small and both have different distribution features on the flange and the web which are perpendicular to one another.

The corresponding von Mises equivalent stress distribution is also calculated in order to determine the final residual stress state, as shown in Fig. 9. It is indicated that, similar to the longitudinal residual stress component, a higher stress concentration is located at the weld zone and surrounding HAZ. The peak value of equivalent stress in the condition of this study is 287 $\mathrm{MPa}$, slightly larger than the yielding strength of base metal of $277 \mathrm{MPa}$ at the room temperature, which indicates that, in the condition used in this study, there exits no serious residual stress in laser+GMAW hybrid T-joint welding of aluminum alloy. In addition, since the aluminum alloy plate is of small thickness, the stress distribution has less change along the thickness direction.

Fig. 10 compares the residual stress component and equivalent stress distributions along the direction perpendicular to the welding bead at different locations on the surface of T-welded specimens. The calculation locations are shown in Fig. 10. In Fig. 10(a), it is seen that, the longitudinal residual stresses in four regions have similar distribution shapes and peak values. In and near the weld zone, large tensile stresses are generated and all the peak values are slightly less than the yield strength of base metal. With distance increasing from weld bead, the tensile stresses decrease sharply. At a distance greater than $15 \mathrm{~mm}$ from weld boundary, the compressive residual stress appears. The stresses in $x$ and $y$ directions at different regions are all much lower, shown in Fig. 10(b) and Fig. 10(c). The maximum peak stress is only $35 \mathrm{MPa}$, which is much less than the yield strength of welded material. As mentioned above, because the flange is perpendicular to the web, a large difference of $x$-directional stress is observed on the flange and web surfaces near the fusion zone, as seen in Fig. 10(b).
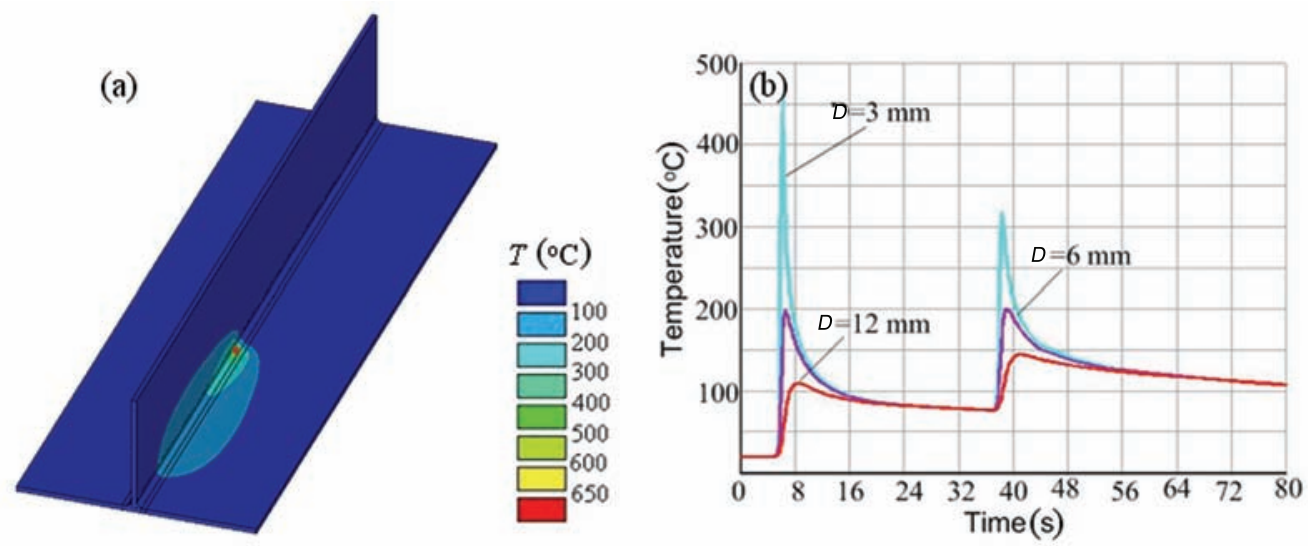

Fig. 7 Temperature field (a) and temperature history (b) in hybrid welding of aluminum alloy T-joint 

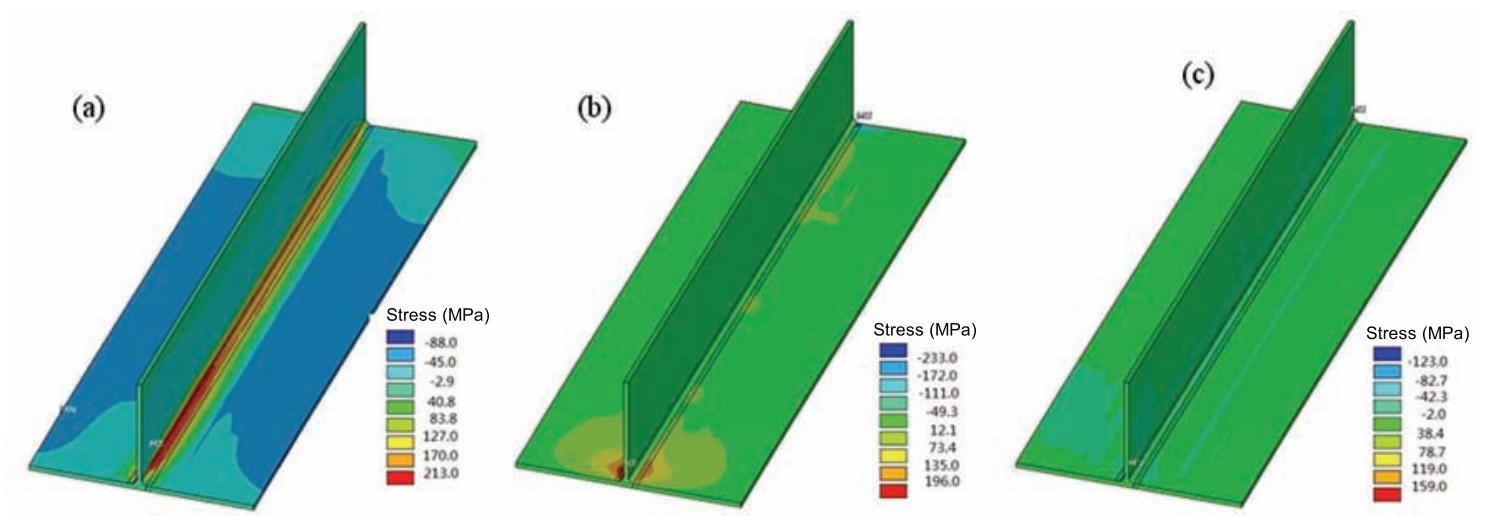

Fig. 8 Contours of residual stress components of the weldment: (a) the stress in $z$ direction (welding direction); (b) the stress in $x$ direction; (c) the stress iny direction
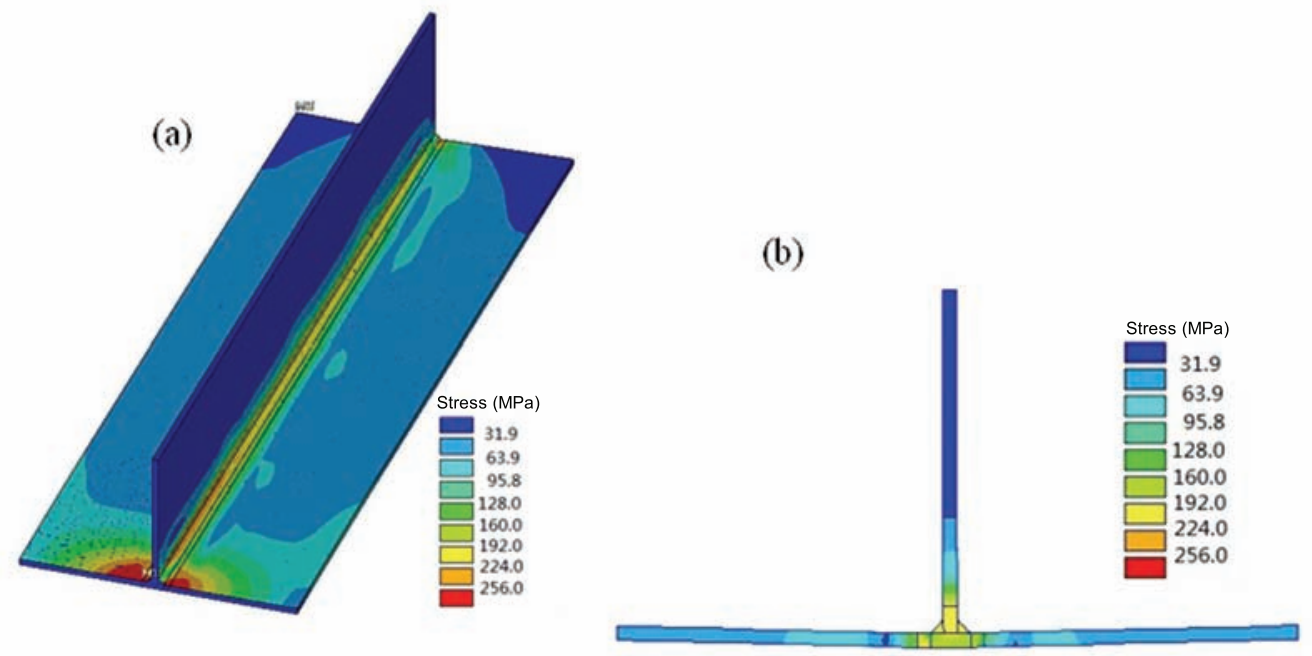

Fig. 9 von Mises equivalent stress distribution of weldment: (a) three-dimensional view; (b) cross section at $z=150 \mathrm{~mm}$

Due to stress concentration, the tensile stress in $x$ direction near the weld toes on the flange surface has a high value. With the distance increasing from weld boundary, it drops greatly. And for the web surfaces, the stresses in $x$ direction for all the points are lower. As to the $y$-directional stress distributions at different locations, the opposite case of the $x$-directional stress distributions emerges, as indicated in Fig. 10(c). Fig. 10(d) compares von Mises equivalent stresses on different surfaces. It is seen that their distribution features are close to each other and are similar to those of longitudinal stresses.

Besides, from Fig. 10, it is also found that there exits a wider area with high residual stress on the web surface at the side of pass II compared to other locations. These phenomena are reasonable. The reason for this is that, during the hybrid both pass welding of T-joint, both sides of the web are heated. Because of small thickness of the aluminum alloy plate and high thermal conductivity, the heat input from pass I can affect greatly the temperature field on the web surface at the pass II side except for heat energy from pass II. Thus, a wider region with high temperature emerges on this surface in welding, leading to a greater zone of thermally induced stress.

\subsection{Analysis of hybrid welding residual distortion}

Fig. 11 shows the contours of calculated displacement components and displacement vector sum in laser+GMAW hybrid welding of aluminum alloy Tjoint. It is seen that, compared with the displacement in the $x$ and $z$ directions, the displacement component in the $y$ direction is relatively large. Owing to the difference of the welding directions between the two welding passes, the displacement components have unsymmetric distributions on the flange surfaces on both sides of the web. Fig. 11(d) presents the distribution of the vector sum of displacement components in hybrid welding of T-joint. It can be found that, similar to the $y$ directional displacements, the vector sum of the displacement increases with the distance increasing from the weld zone.

Fig. 12 shows the schematic diagram of the calculation locations. Fig. 13 presents the deflection distributions along the lines 1, 2, 3, 4 and 5 defined in 

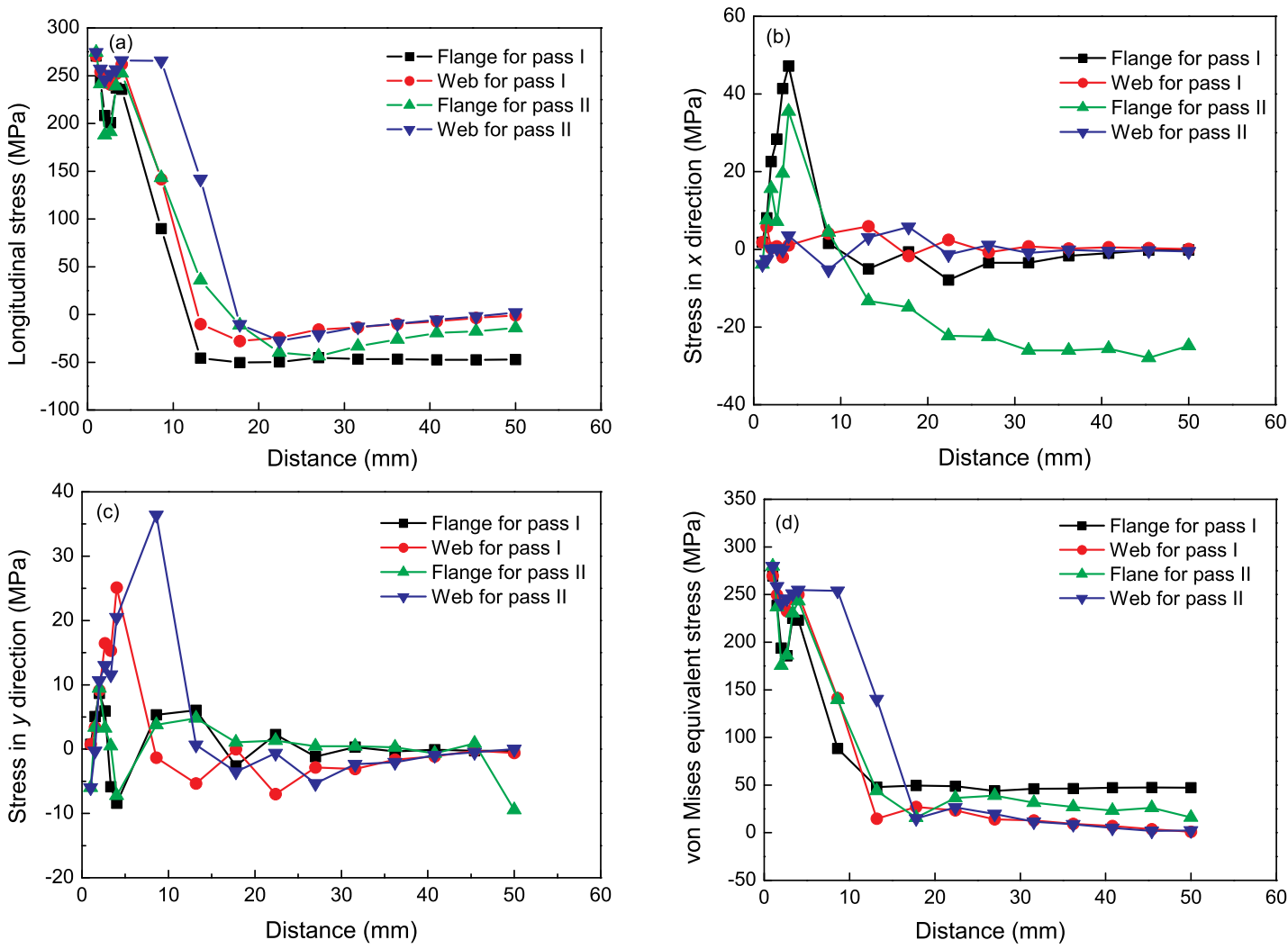

Fig. 10 Stress distributions at different locations on the surface of workpiece: (a) longitudinal stress; (c) stress in $x$ direction; (b) stress in $y$ direction; (d) von Mises stress
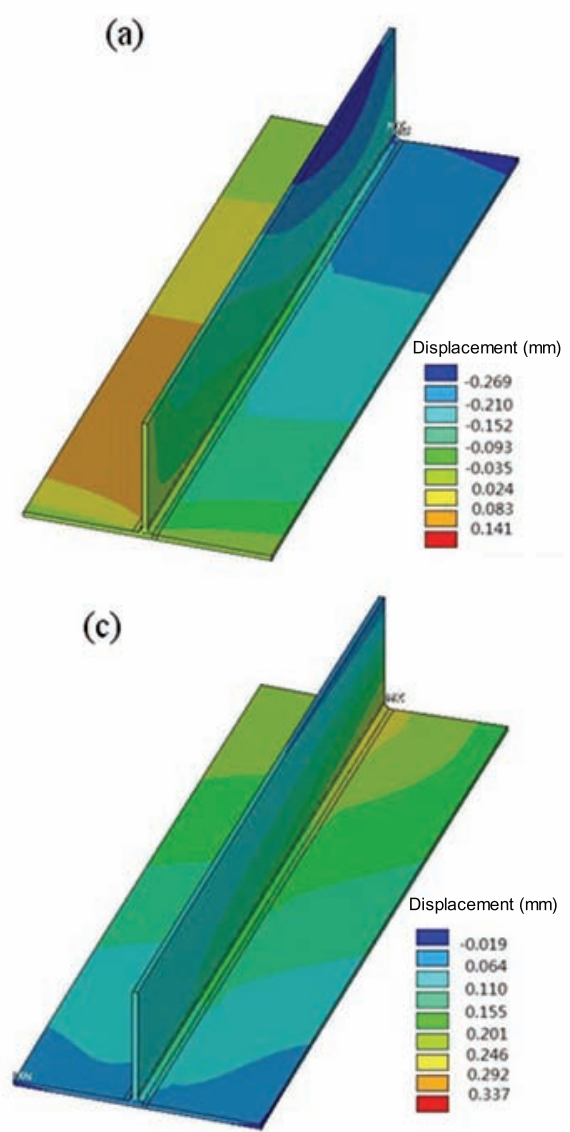

(b)

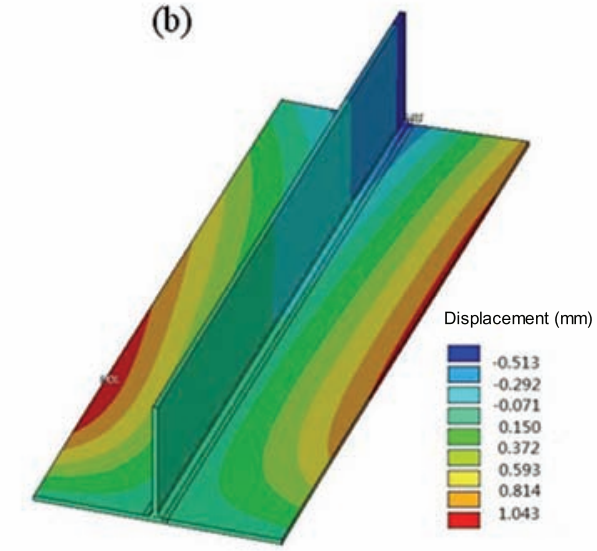

(d)

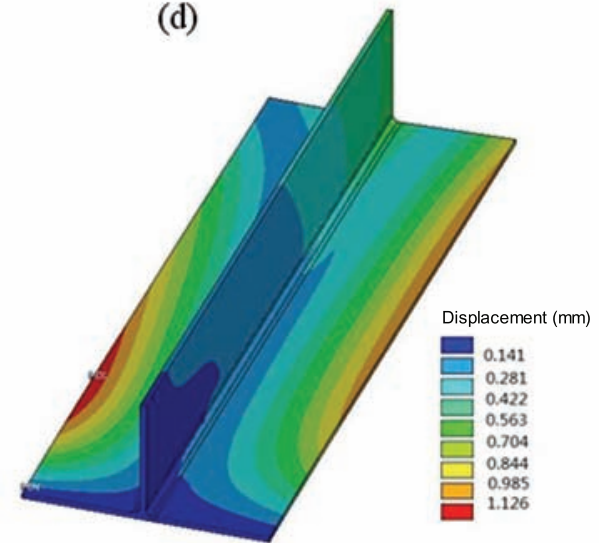

Fig. 11 Displacement components and their vector sum of hybrid welded T-joint of aluminum: (a) $x$-displacement; (b) $y$-displacement; (c) $z$-displacement; (d) displacement vector sum 


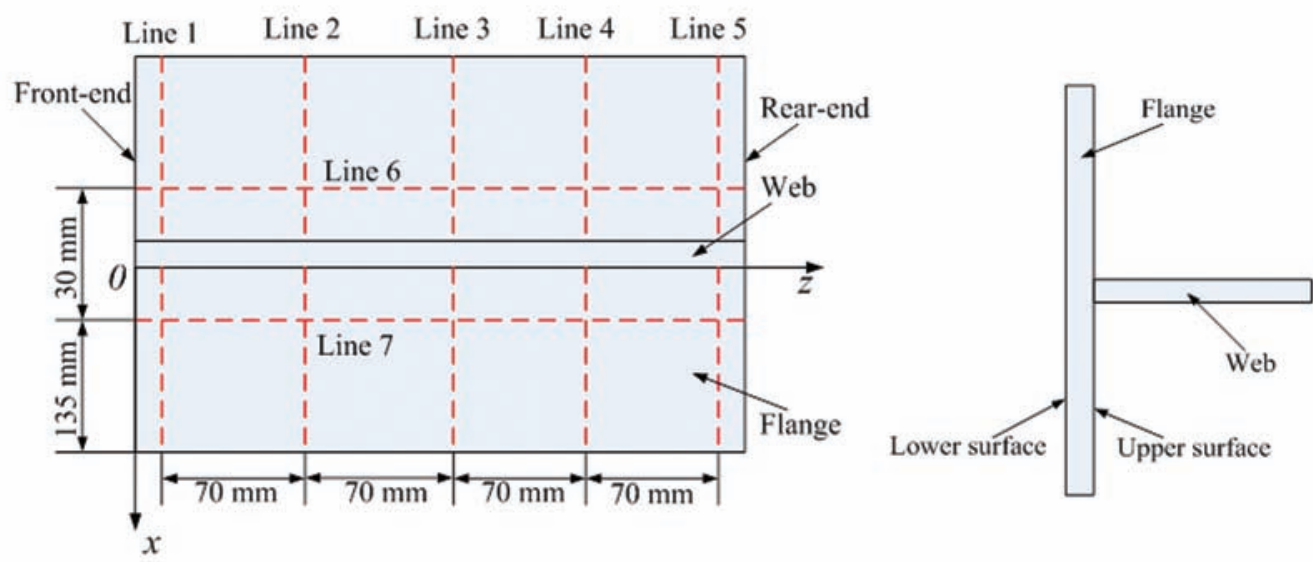

Fig. 12 Schematic diagram of the calculation locations

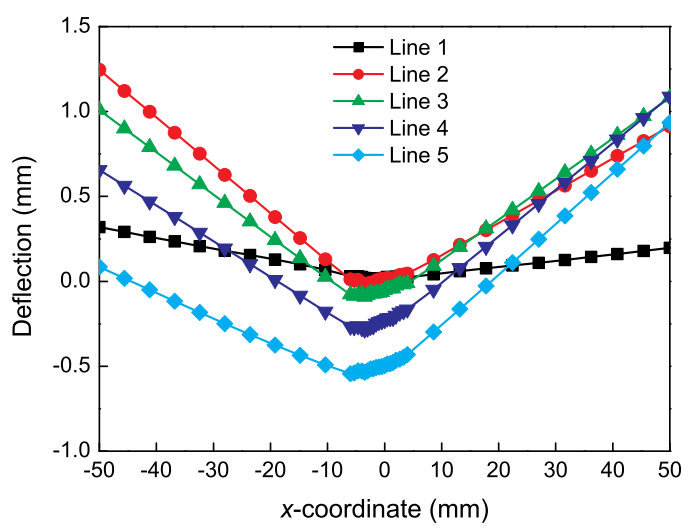

Fig. 13 Deflection distributions along lines 1, 2, 3, 4 and 5

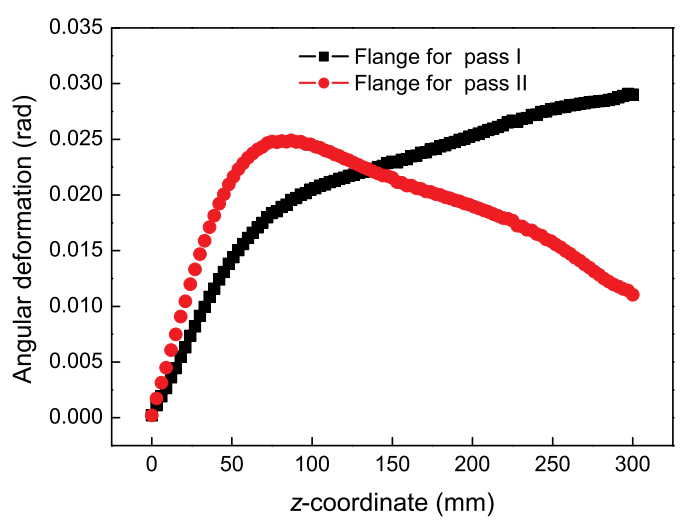

Fig. 14 Angular deformation distribution along the $z$ direction

Fig. 12. Fig. 14 gives the angular distortion distribution along the $z$ direction. As stated above, deformations on the flange at both sides of the web are not symmetrical. Compared to those on the other locations, the deflection near the front end of the weldment is lower, and a small angular distortion is generated in this region. And, for the flange at the side of pass I, the angular distortion gradually increases with

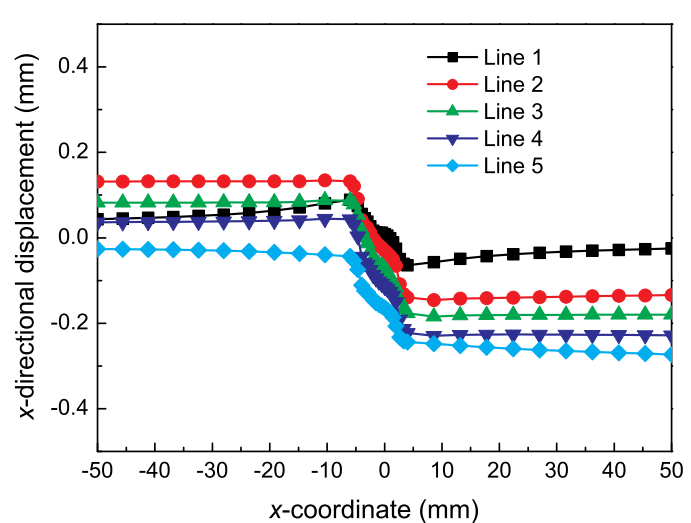

Fig. $15 x$-directional displacement along lines 1, 2, 3, 4 and 5

distance from the front end of weldment; regarding the flange at the pass II side, along the $z$ direction, angular deformation has a sharp growth at first and then decreases to some extent. This phenomenon is attributed to the moving heat source and the welding direction. In this study, a single-sided welding process is used and the two welding passes are performed in the opposite welding direction. With the welding heat source moving, the angular distortion rises with distance from the weld start. Besides, deformation of the flange at the pass II side near the weldment front-end is affected more largely by the constraints from the reinforcements of two welding passes, therefore resulting in a lower value. Fig. 15 compares the $x$-directional displacements at the corresponding locations. Similarly, with the growth of distance from the weldment front-end, a rising $x$-displacement on the flange at the side of welding pass I is observed. And for the flange at the pass II side, the displacement in $x$ direction is firstly raised and then is decreased.

The transverse shrinkages in the upper and lower surfaces of the flange are also calculated, as seen in Fig. 16. It should be noted that the values of the transverse shrinkage are obtained on the basis of the difference of transverse displacements between lines 


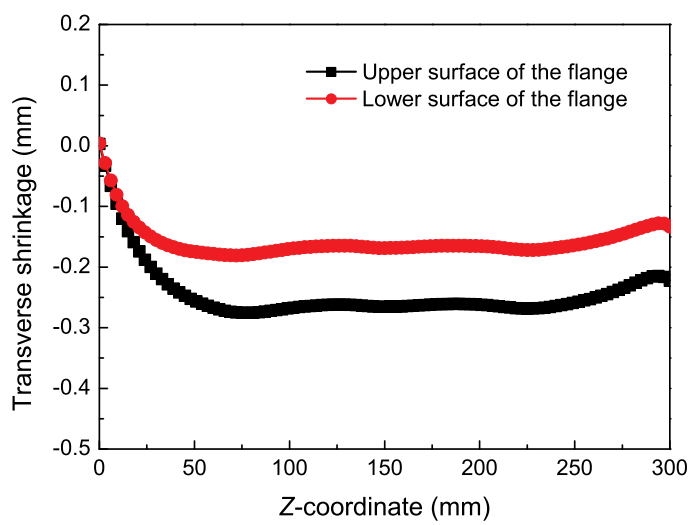

Fig. 16 Transverse shrinkage on the upper and lower surfaces of the flange

6 and 7 defined in Fig. 12. From Fig. 16, it is indicated that there is no expansion taking place on both the upper and lower surfaces of the flange after welding. The transverse shrinkage on the upper surface of the flange near the weldment front-end is almost the same as that on the corresponding lower surface and both are quite small. With distance away from the weldment front-end, both the magnitudes firstly increase and then retain basically stable, and meanwhile a difference between them emerges. This difference reaches its peak value of $0.1 \mathrm{~mm}$ at $z=150 \mathrm{~mm}$ and its change is small along the $z$ direction. The distribution feature of transverse shrinkage on the flange in hybrid welding of alloy T-joint shows the flange shrinks uniformly through the thickness, thus leading to angular distortion of the flange during welding. But, it is also clearly found that, in hybrid welding of aluminum alloy $\mathrm{T}$-joint, the welding deformation is relatively small.

\section{Conclusions}

(1) A 3-D finite element model is developed to investigate the residual stress and deformation in laser+GMAW hybrid welding of aluminum alloy Tjoint. The heat source model considers the influence of joint form and welding torch inclination on heat flux distribution, and the calculated weld geometry and sizes agree well with the experimental data.

(2) High tensile residual stress in the welding direction is located in the weld zone and its vicinity, and its peak value is lower than the yield strength of base metal. The corresponding von-Mises equivalent stress has the similar distribution feature with a peak value slightly larger than the yield strength of aluminum alloy. Besides, there exits a wider area with high residual stress on the wed surface at the pass I side.

(3) Under the welding condition of this study, a small welding angular distortion emerges near the front-end of T-specimens, and relatively large ones take place in the middle and rear parts of weldment. With the distance away from the weldment front-end, the transverse shrinkages on both upper and lower surface of the flange firstly increase and then remain basically stable and their difference has the similar distribution.

(4) The developed thermo-mechanical finite element model could be further used to optimize the process parameters in laser+GMAW hybrid welding of T-joint.

\section{Acknowledgements}

This work was supported by the Sino-Russian Cooperation Research Project of China (No. 2009DFR50170), the National Natural Science Foundation of China (No. 51105182) and the College Natural Science Foundation of Jiangsu Province (No. 11KJB460004).

\section{REFERENCES}

[1] S.J. Maddox, Int. J. Fatigue 25 (2003) 1359.

[2] S.H. Zhang, K. Chen, S.R. Xiao and T.C. Zuo, Laser J. 26(4) (2005) 45.

[3] W.S. Zhou and J.S. Yao, Welding of Aluminum and Its Alloy, China Machine Press, Beijing, 2006, p.55.

[4] J. Defalco, Weld. J. 86(10) (2007) 47.

[5] C.J. Jiao, Master Thesis, Beijing Industry Universty, Beijing, 2009.

[6] T. Graf and H. Staufer, Weld. J. 83(3) (2004) 82.

[7] C. Bagger and F.O. Olsen, J. Laser Appl. 17(1) (2005) 2.

[8] A. Mahrle and E. Beyer, J. Laser Appl. 18(3) (2006) 169.

[9] M. Rayes, C. Walz and G. Sepold, Weld. J. 83(5) (2004) 147.

[10] A. Alessandro, F. Alessandro, O. Leonardo and C. Giampaolo, Optics Laser Technol. 44 (2012) 1485.

[11] G.X. Xu, C.S. Wu, G.L. Qin, X.Y. Wang and S.Y. Lin, Acta Metall. Sin. 45 (2009) 107 (in Chinese).

[12] G.X. Xu, C.S. Wu, G.L. Qin, X.Y. Wang and S.Y. Lin, Int. J. Adv. Manuf. Technol. 57(1-4) (2011) 245.

[13] J. Zhou and H.L. Tsai, Int. J. Heat. Mass. Trans. 51 (2008) 4353.

[14] J.H. Cho and S.J. Na, Weld. J. 88(2) (2009) 35.

[15] T. Zhang, C.S. Wu, G.L. Qin, X.Y. Wang and S.Y. Lin, Comput. Mater. Sci. 47 (2010) 848.

[16] F.R. Kong, J.J. Ma and R. Kovacevic, J. Mater. Process Technol. 211 (2011) 1102.

[17] Y.T. Cho, W.I. Cho and S.J. Na, Optics Laser Technol. 43 (2011) 711.

[18] G.X. Xu, C.S. Wu, G.L. Qin and X.Y. Wang, Acta Metall. Sin. 48 (2012) 1033 (in Chinese).

[19] D.A. Deng, Mater. Des. 30 (2009) 359.

[20] Y.G. Duan, Master Thesis, Shanghai Jiaotong University, Shanghai, 2003. (in Chinese) 